\title{
Body Mass Index Assessment of Health Care Professionals in a Primary Care Setting in Portugal: a Cross Sectional Study
}

\author{
Avaliação do Índice de Massa Corporal em Profissionais de Saúde dos \\ Cuidados de Saúde Primários: um Estudo Transversal
}

Inês CAMPOS-MATOS ${ }^{1}$, André PERALTA-SANTOS ${ }^{2}$, Bernardo GOMES ${ }^{3}$, Gustavo BORGES ${ }^{4}$, Pedro AGUIAR

Acta Med Port 2014 Sep-Oct;27(5):609-614

\begin{abstract}
Introduction: Obesity is an important public health problem because it is a risk factor for numerous diseases and is associated with a higher death risk. Evidence concerning the prevalence of excess weight in health professionals is scarce and this group is often overlooked in weight interventions programs. This paper aims to estimate the prevalence of obesity and overweight among Portuguese primary health care professionals and to describe differences between occupational groups.

Material and Methods: This was a cross sectional study based on a primary care setting in Portugal in 2011. We collected data on occupation, age, sex and height of professionals from four primary care centers. We did a descriptive analysis of the main variables and an analysis of covariance to compare mean Body Mass Index.

Results: Our sample represented $52.8 \%$ of the total population of the four primary care centers, and $38.6 \%$ were overweight and $16.9 \%$ were obese. When adjusted for age and gender, health service personnel had the highest average Body Mass Index, followed by nurses, physicians, and superior technicians, in that order.

Discussion: Although we can't ensure the generalisation of the results and cannot exclude the possibility of sampling bias, these results suggest high prevalence obesity and overweight in workers of primary health care in Portugal.

Conclusion: In this primary care setting more than half of the health care professionals were overweight or obese. Tailored interventions might be needed to tackle this issue.
\end{abstract}

Keywords: Body Mass Index; Health Personnel; Obesity; Portugal; Primary Health Care; Prevalence.

\section{RESUMO}

Introdução: A obesidade é um importante problema de saúde pública por ser fator de risco para numerosas doenças e estar associada a maior risco de morte. A evidência sobre a prevalência de excesso de peso em profissionais de saúde é escassa e este grupo é frequentemente esquecido em programas de intervenção. Este trabalho tem como objetivo estimar a prevalência de obesidade e excesso de peso entre os profissionais nos cuidados de saúde primários portugueses e descrever diferenças entre os grupos profissionais.

Material e Métodos: Estudo descritivo transversal em contexto de cuidados de saúde primários em Portugal em 2011. Foram recolhidos dados sobre a ocupação, idade, sexo e altura de profissionais de quatro agrupamentos de centros de saúde. Fizemos uma análise descritiva das principais variáveis e uma análise de covariância para comparar o Índice de Massa Corporal.

Resultados: O grupo de conveniência representou $52,8 \%$ do total da população dos quatro agrupamentos de centros de saúde, sendo que $38,6 \%$ tinham excesso de peso e 16,9\% eram obesos. Após ajustamento por idade e sexo, os assistentes técnicos e operacionais tiveram a média mais elevada de Índice de Massa Corporal.

Discussão: Apesar de não se poder garantir a generalização dos resultados nem excluir a possibilidade de viés de amostragem, estes resultados sugerem uma elevada prevalência de obesidade e excesso de peso nos profissionais dos cuidados primários de saúde em Portugal.

Conclusão: Neste contexto de cuidados de saúde primários mais de metade dos profissionais de saúde apresentavam excesso de peso ou obesidade. É possível que sejam necessárias intervenções específicas.

Palavras-chave: Índice de Massa Corporal; Pessoal de Saúde; Obesidade; Portugal; Cuidados de Saúde Primários.

\section{INTRODUCTION}

The prevalence of obesity is rising globally and has risen threefold or more in Europe since the 1980's, reaching an estimated 150 million adults by $2010 .{ }^{1}$ Obesity and overweight are an important public health problem and were estimated to be, in 2004 , responsible for $8.4 \%$ of deaths in high income countries and the third leading cause of gained disability adjusted life years (DALYs) in high income countries. ${ }^{1}$

The fourth Portuguese National Health Survey, ${ }^{2}$ based on nationwide self-reported data of 41193 individuals, estimated that, in $2005 / 2006,15.2 \%$ of the Portuguese adult population were obese and $35.7 \%$ were overweight. Women had a slightly higher prevalence $(16 \%$ versus $14.3 \%$ ) and people with less than 5 years of schooling were significantly more likely to be obese (21.4\% prevalence). Prevalence also increased with age and over time (the previous National Health Survey, done in 1998, had estimated $12 \%$ prevalence in the Portuguese mainland).

\footnotetext{
1. Agrupamentos de Centros de Saúde de Oeste Norte. Caldas da Rainha. Portugal.

2. Agrupamentos de Centros de Saúde Grande Lisboa VII. Amadora. Portugal.

3. Agrupamentos de Centros de Saúde Entre Douro e Vouga I. Santa Maria da Feira. Portugal.

4. Agrupamentos de Centros de Saúde Grande Porto III. Maia. Portugal.

5. Departamento de Epidemiologia e Estatística. Escola Nacional de Saúde Pública. Universidade Nova de Lisboa. Lisboa. Portugal.

Recebido: 07 de Janeiro de 2014 - Aceite: 28 de Abril de 2014 | Copyright $\odot$ Ordem dos Médicos 2014
} 
No data was collected on people's occupation. Other authors, like Carmo et $\mathrm{al}^{3}$ reported similar prevalences of obesity: $14.2 \%$ obese, $34.4 \%$ overweight and with the same pattern of increasing obesity with age although with conflicting results regarding the gender prevalences (higher in men rather than in women).

People often identify their general practitioner (GP) as their most trusted source of health related information and behavioral change has been seen to have a stronger association with GP's advice when compared to written information on its own. ${ }^{4}$ Additionally, one of the most important predictors of giving lifestyle advice to patients is the practice of a healthy lifestyle by the GP him or herself. ${ }^{5}$ Empiric evidence supports this idea. Bleich et $\mathrm{al}^{6}$ found supportive evidence for an important impact of physician's Body Mass Index (BMI) on his or her practice. Not only were physicians with normal BMI more likely to initiate a conversation about weight loss with their obese patients, but they also had a higher confidence in their own ability to provide advice on this issue. Additionally, when the patients' body weight exceeded that of the physician, physicians were more likely to record an obesity diagnosis and to initiate a conversation about weight loss. ${ }^{6}$ Health professionals' health is, therefore, of key importance to implement interventions targeting obesity in health care. Hence, it is important to know the prevalence of obesity in health care professionals.

This paper aims to estimate the prevalence of obesity and overweight among Portuguese primary health care workers in the study places, and describe differences between occupational groups, sex and age. This includes physicians (GPs and Public Health doctors), nurses, health technicians (such as oral hygienists, environmental health technicians, among others) and other health service personnel (mainly with secretarial occupations). Although there are occasional studies of the prevalence of obesity and overweight in health professionals, to the best of our knowledge there is no study in Portuguese health professionals. This study is an important addition to current knowledge because extrapolation from other studies would be inadequate and the tailoring of interventions should be specific to the Portuguese context.

\section{MATERIAL AND METHODS}

This was a cross sectional study based on a primary care setting. This study was carried out during 2011 in four Agrupamentos de Centros de Saúde (ACES) - Amadora, Oeste Norte, Entre Douro e Vouga I and Maia (Fig. 1). The data was collected specifically for this study between July and September of 2011; in Oeste Norte the data was already available for that same year from the occupational office records. These records had information collected during an occupational medicine consultation, carried out by a doctor and a nurse, where weight and height were measured. All the professionals with a contract with the primary care center were eligible for the study. Pregnant women were excluded. The total population had 1347 eligible individuals distributed between the four study centers. The eligible professionals were personally invited to participate. All participants gave informed consent. Professionals who were absent from work or refused to participate were not included. Reasons of absence or refusal were not collected. We collected data on the occupation, age, sex, height and weight. The World Health Organization (WHO) definition and categorization of BMI was used. ${ }^{1}$

The demographic variables were collected by interview (occupation, age and sex) and physical measurements were done with a calibrated stadiometer (sensitivity of $0.1 \mathrm{~cm}$ ) and a scale (sensitivity of $0.1 \mathrm{~kg}$ ). Not all the stadiometers and scales in the different study locations were of the same brand or model. However, we considered that in the measurement of BMl a small systematic error that might arise from different models was acceptable. The measurement procedures were standardized between the study coordinators in the different study sites.

We did a descriptive analysis of the main variables, using proportions and means. We used Chi-Square test for differences of proportions. We used analysis of covariance, ANCOVA, to compare the means of BMI by occupation, age, sex and study location. Associations that were not statistically significant at the 0.05 level were excluded from the multivariable model. For multiple comparisons between groups we used the Bonferroni method. We used SPSS $20^{\circ}$ to do the statistical analysis.

\section{RESULTS}

Our sample was constituted by $52.78 \%$ of the total population (712 individuals). The proportion of individuals included in the sample had a considerable variation between study places: Oeste Norte had the lower participation with $32.94 \%$ and Maia had the highest with $82.12 \%$ (Table 1).

The study-group had $82.4 \%$ women, who had a mean age of 44.9 years with a standard deviation (SD) of 10.2 years. Men had a mean age of 47.7 with a SD of 11.9 years. The mean age of the sample between centers was fairly homogenous; Maia had the lowest mean age (42.9 years) and was the only one in which there was a statistically significant difference from all the other places. In the other places mean age varied between 45.6 years in Entre Douro Vouga I and 48.5 years in Oeste Norte. As Table 2 demonstrates, nurses and superior technicians were the youngest groups with 39.8 and 41.3 mean age, respectively, and health service personnel and physicians were the oldest with 47.8 and 49.3 years.

Considering the BMI classification, $38.4 \%$ of the health professionals were overweight and $16.9 \%$ obese. The prevalence of obesity was the highest among health service personnel, with $23.3 \%$, whilst physicians had $16.3 \%$ and nurses $11.6 \%$. On the other side of the spectrum were the superior technicians, with a prevalence of $6.2 \%$ (Table 2).

The mean BMI, by occupation, revealed that health service personnel and physicians had the highest values, both within the excess weight definition (27.4 and $26.4 \mathrm{~kg} /$ $\mathrm{m}^{2}$, respectively). Nurses and superior technicians had 


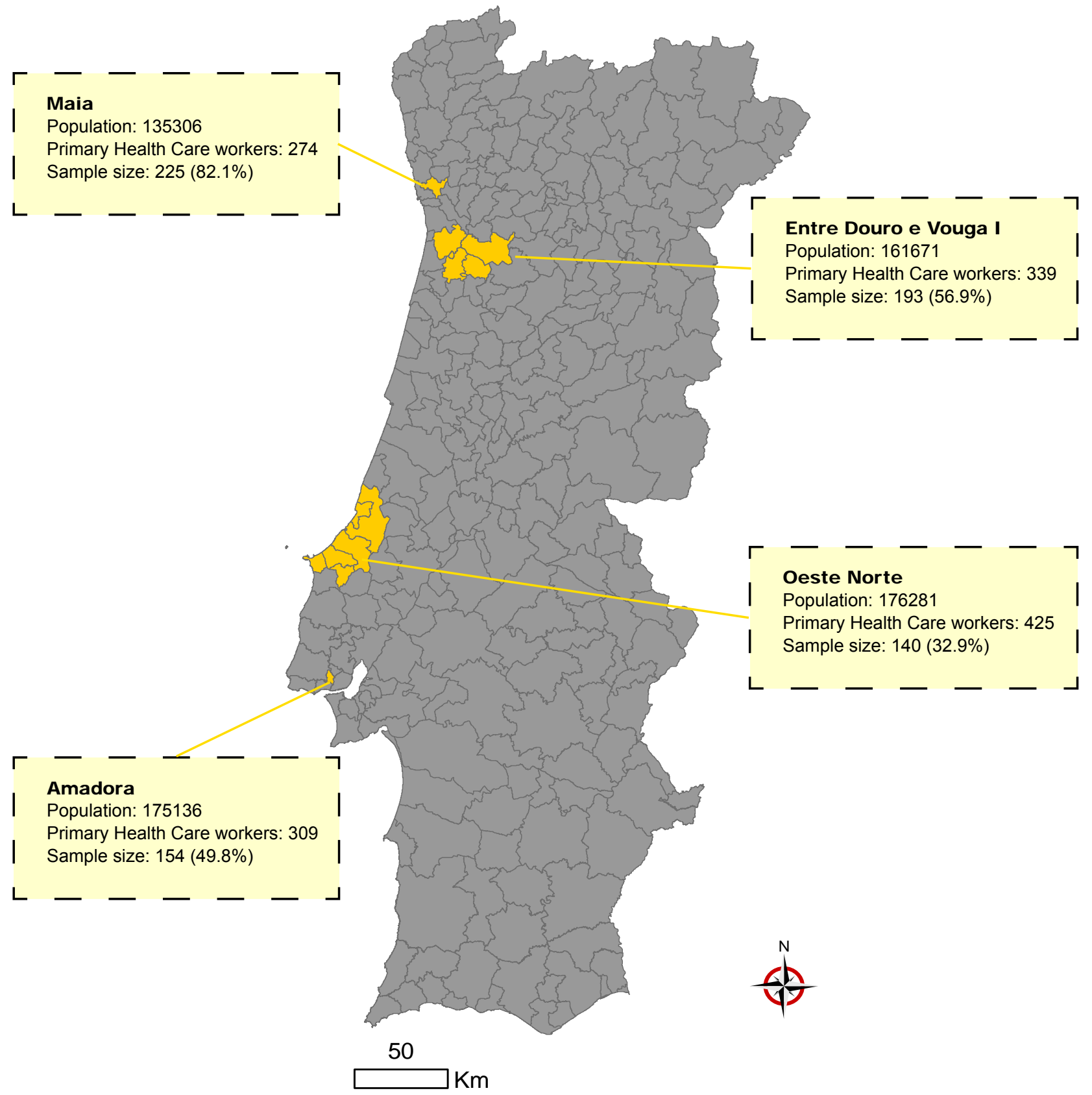

Figure 1 - Study locations

the lowest values, with the mean BMI within the normal definition (24.8 and $23.5 \mathrm{~kg} / \mathrm{m}^{2}$, respectively).

In Table 3 we can see the influence of the variables of interest on BMI in the multivariable analysis. The study location was not statistically significant - there is no difference in the BMI between study locations when controlled for age, sex and occupation (not represented in the table).

For every added 10 years of age the BMI increases, on average, $1.2 \mathrm{~kg} / \mathrm{m}^{2}$. Men had an average $1.8 \mathrm{~kg} / \mathrm{m}^{2}$ higher $\mathrm{BMI}$ than women. If we use the superior technicians as a reference, physicians and nurses have a $1.6 \mathrm{~kg} / \mathrm{m}^{2}$ higher $\mathrm{BMI}$ and health service personnel have a $3.3 \mathrm{~kg} / \mathrm{m}^{2}$ higher BMI.

In Table 4, we adjust the mean BMI values by occupation for age and gender. As a result, the health service personnel still have the highest BMI values (this was the only occupation statistically different from the others).

\section{DISCUSSION}

The results showed that, for this sample, the mean BMI of the health professionals was above normal and within the definition of overweight $\left(26.1 \mathrm{~kg} / \mathrm{m}^{2}\right)$ and that $38.6 \%$ were overweight and $16.9 \%$ were obese. When BMI was controlled for age, sex, and occupation there were no differences between study places. Increasing age was associated with an increasing BMI and men had a higher BMI than women. Superior technicians had the lowest BMI, physicians and nurses had around $1.6 \mathrm{~kg} / \mathrm{m}^{2}$ higher BMI, 
Table1 - Summary table of the population and sample characteristics by sex, occupation and location

\begin{tabular}{|c|c|c|c|c|c|c|c|c|c|c|}
\hline \multirow[b]{2}{*}{ Location } & \multirow[b]{2}{*}{ Pop } & \multicolumn{2}{|l|}{ General } & \multicolumn{2}{|c|}{$\begin{array}{l}\text { Female } \\
\text { Gender }\end{array}$} & \multirow{2}{*}{\multicolumn{2}{|c|}{$\mathrm{HSP}^{1}$}} & Occupation & $n(\%)$ & \multirow[b]{2}{*}{ Sup Tec ${ }^{4}$} \\
\hline & & Sample & $\%$ tot. pop & \multicolumn{2}{|c|}{$n(\%)$} & & & Nurse $^{2}$ & Physician $^{3}$ & \\
\hline Maia & 274 & 225 & 82.1 & \multicolumn{2}{|c|}{$185(82.2)$} & \multicolumn{2}{|c|}{$68(30.2)$} & 77 (34.2) & $72(32.0)$ & $8(3.6)$ \\
\hline Amadora & 309 & 154 & 49.8 & \multicolumn{2}{|c|}{$125(85.0)$} & \multicolumn{2}{|c|}{$51(33.1)$} & $41(26.6)$ & $46(29.9)$ & $16(10.4)$ \\
\hline Oeste N & 425 & 140 & 32.9 & \multicolumn{2}{|c|}{$113(80.7)$} & \multicolumn{2}{|c|}{$63(45.0)$} & $38(27.1)$ & $26(18.6)$ & $13(1.8)$ \\
\hline Douro V & 339 & 193 & 56.9 & \multicolumn{2}{|c|}{$164(85.0)$} & \multicolumn{2}{|c|}{$81(42.0)$} & $59(30.6)$ & $46(23.8)$ & $7(3.6)$ \\
\hline Total & 1347 & 712 & 52.8 & \multicolumn{2}{|c|}{$587(82.4)$} & \multicolumn{2}{|c|}{$263(36.9)$} & $215(30.2)$ & $190(26.7)$ & $44(6.2)$ \\
\hline \multirow{3}{*}{ Occupation } & & \multicolumn{9}{|c|}{ Body Mass Index } \\
\hline & Age (SD) & $\begin{array}{l}\text { Mean } \\
\text { (SD) }\end{array}$ & $95 \% \mathrm{Cl}$ & & Norn & & & Overweight & & Obesity \\
\hline & & & & $n$ & & $5 \% \mathrm{Cl})$ & $n$ & $\%(95 \% \mathrm{Cl})$ & $n$ & $\%(95 \% \mathrm{Cl})$ \\
\hline HSP & $47.8(10.0)$ & $27.4(4.6)$ & $26.8-27.9$ & 81 & 30.9 & $5.6-36.6)$ & 120 & $45.8(39.7-51.7$ & 61 & $23.3(18.5-28.7)$ \\
\hline Nurse & $39.78(8.8)$ & $24.8(3.9)$ & $24.3-25.3$ & 129 & 60.0 & $3.3-66.3)$ & 61 & $28.4(22.7-34.7$ & 25 & $11.6(8.0-16.6)$ \\
\hline Physician & $49.3(10.7)$ & $26.4(4.3)$ & $25.8-27.0$ & 75 & 39.5 & $2.8-46.5)$ & 84 & $44.2(37.3-51.3)$ & 31 & $16.3(11.7-22.2)$ \\
\hline Superior $\mathrm{T}$ & $41.3(9.2)$ & $23.5(3.3)$ & $23.5-25.5$ & 33 & 75.0 & $0.1-85.4)$ & 8 & $18.2(9.5-32.0)$ & 0) & $6.8(2.4-18.3)$ \\
\hline Total & $45.4(10.6)$ & $26.1(4.4)$ & $25.8-26.4$ & 318 & 44.7 & $1.1-48.3)$ & 273 & $38.4(34.8-42.0$ & 0) 120 & $16.9(14.2-19.8)$ \\
\hline
\end{tabular}

1 - HSP/Health Service Personnel: health professional responsible for secretary office, cleaning work; 2 - Nurse: Professional with a nursing degree; 3 - Physician: Professional with a medical degree, specialist or resident in general practice or public health; 4 - Superior technician: professional with a higher degree such as environment technician, oral hygiene, psychology.

and finally health service personnel had more than $3 \mathrm{~kg} / \mathrm{m}^{2}$ higher BMI, when adjusted for age and sex.

This study was the first to evaluate the BMI of health professionals in Portugal and it allowed controlling the results for age, gender and occupation (allowing less biased estimates). These results emphasize the need to reinforce measures of healthy behaviors in this group.

The main limitation of this study is related with the way the samples were assembled. Although we had a reasonable participation in the study $(52.8 \%)$, we cannot exclude the possibility of sampling bias. The differences in participation between study sites can be attributed to the fact that the study was performed in August, when most personal is absent for holiday. One would also expect that Oeste Norte would have a higher participation rate because data collection was integrated in the Occupational Medicine Office; however, this office was still in the beginning of its activity, which can explain the low proportion of professionals surveyed. Also, in Oeste Norte the data was not collected for the specific purpose of this study, which could lead to misclassification of individuals regarding their BMI. We believe this is not the case, that misclassifications are negligible because the measurements were done by health professionals and following a protocol for weight and height measurements.

It cannot be assumed what kind of effect the sampling 
Table 3 - BMI relation between the co variables age, sex and occupation (one way analysis and covariance)

\begin{tabular}{|c|c|c|c|c|c|c|}
\hline \multirow{2}{*}{$\begin{array}{l}\text { Variable } \\
\text { Age }\end{array}$} & & \multirow{2}{*}{$\frac{B}{0.12}$} & \multicolumn{3}{|c|}{ 95\% $\mathrm{Cl}$ (Upper and Lower range) } & \multirow{2}{*}{$\begin{array}{l}\boldsymbol{p} \text { value } \\
<0.001\end{array}$} \\
\hline & & & 0.09 & & 0.15 & \\
\hline \multirow{2}{*}{ Sex } & Men & 1.79 & 0.96 & & 2.62 & $<0.001$ \\
\hline & Women & Ref. & & & & \\
\hline \multirow{4}{*}{ Occupation } & HS Personnel & 3.26 & 1.94 & & 4.58 & $<0.001$ \\
\hline & Nurse & 1.58 & 0.26 & & 2.90 & $<0.05$ \\
\hline & Physician & 1.56 & 0.19 & & 2.93 & $<0.05$ \\
\hline & Superior $\mathrm{T}$ & Ref. & & & & \\
\hline \multicolumn{2}{|l|}{ Intercept } & 16.60 & 18.32 & & 20.08 & $<0.001$ \\
\hline \multicolumn{7}{|c|}{$\begin{array}{l}\text { - HSP/ Health Service Personnel: health professional responsible for secretary office, cleaning work; } 2 \text { - Nurse: Professional with a nursing degree; } 3 \\
\text { a medical degree, specialist or resident in general practice or public health; } 4 \text { - Superior technician: professional with a higher degree such as environr } \\
\text { psychology. Ref.: reference group for comparison. } \\
\text { Table } 4 \text { - Mean BMI stratified by Occupation and adjusted for age and gender (one way analysis and covariance) }\end{array}$} \\
\hline \multicolumn{2}{|l|}{ Variable } & Mean & SD & & $\mathrm{Cl}$ & $p$ value \\
\hline \multirow{4}{*}{ Occupation } & HS Personnel (Ref) & 27.2 & 0.25 & 26.7 & 27.7 & \\
\hline & Nurse & 25.6 & 0.29 & 25.0 & 26.1 & $<0.001$ \\
\hline & Physician & 25.5 & 0.31 & 24.9 & 26.2 & $<0.001$ \\
\hline & Superior $\mathrm{T}$ & 24.0 & 0.62 & 22.8 & 25.2 & $<0.001$ \\
\hline
\end{tabular}

bias would have on the prevalence of obesity and overweight because it is not clear why some did refuse to participate or were absent from their workplace. In fact, we acknowledge the absence of the information regarding refusal is a pitfall of this study.

The conciliation of the results with the existing evidence of the Carmo study ${ }^{3}$ did not bring any surprises: men had higher BMI and age was positively related with BMI. Occupation, which can be a proxy of educational attainment (physicians, nurses and superior technicians all have a higher degree, whereas health service personnel rarely do) and income, is an indicator of socioeconomic level. Clearly health service personnel have the highest mean BMI after adjustment for age and gender. This can be due to the influence of the socioeconomic factor in the BMI.

Chou and Johnson ${ }^{7}$ also showed differences between occupational groups, with more differentiated occupations (like physicians, dentists and pharmacists) having lower obesity prevalence than other groups. This is consistent with Caban et al data that showed a higher prevalence of obesity in health service personnel and lower in healthdiagnosing occupations, also in the US. ${ }^{8}$

Another interesting finding was that after adjusting for age, sex and occupation, no difference was found between study places. Homogeneity between study places reinforces the consistency of the study and leads us to speculate that the mix of obesity determinants should be the same. Consequently, the interventions that address the problem of obesity in health professionals can be planned taking into account this likely homogeneity.

This study shows, for the first time, the high prevalence of obesity and overweight among Portuguese health care personnel. It also reinforces the association between BMI and age and gender, highlighting the importance of adjusting for these variables when stratifying by occupational groups.

Formally we cannot ensure the generalization of the results to the study population because we did not have a representative sample. We do not know what is the distribution by age, occupation and sex in the study population. Even though these results are consistent with the existing evidence and only a small discrepancy exists comparing the values with the ones showed in population based studies, ${ }^{2,3}$ comparability is very limited.

Future research should expand the study places to ensure a wider representation of the country. It would also be interesting to compare the prevalence of obesity with a hospital setting. Besides research, we find the need for planned interventions for weight management tailored to the specific needs of health professionals. The lack of proactive measures to prevent obesity in the study places may favor obesogenic environments. These results should bring some attention to health worker's health. Health workers, given 
the expected depth of their knowledge about obesity and overweight, are likely to benefit more from interventions focused on motivational aspects rather than in health and dietary education.

\section{CONCLUSIONS}

In this study, in a primary care setting $38.4 \%$ of the health professionals were overweight and $16.9 \%$ obese. The mean $\mathrm{BMI}$ for this population was above normal and within the definition of overweight. BMI was positively associated with being of older age, being male and belonging to the health service personnel.

\section{ACKNOWLEDGMENTS}

The authors would like to acknowledge Carlos Daniel and Pedro Serrano for the important inputs, to the tutors of their residency program for the help in the implementation of the study as well as to the health professionals working in the study places for their collaboration.

They would also like to thank the Public Health Residency Program Coordination for setting this research in motion.

No particular funding was sought for this research or paper writing.

\section{CONFLICTS OF INTEREST}

None declared.

\section{FUNDING SOURCES}

This paper had no source of support.

Presented as poster at the 6th European Public Health Conference: Health in Europe: are we there yet? Learning from the past, building the future; SQUARE Meeting Centre, Brussels, 13 - 16 November 2013.

\section{REFERENCES}

1. World Health Organization. The challenge of obesity in the WHO European Region and the strategies for response: summary. Copenhagen: WHO Regional Office for Europe; 2007.

2. Instituto Nacional de Saúde Doutor Ricardo Jorge. Inquérito Nacional de Saúde 2005/2006 [National Health Survey 2005/2006]. Lisbon: INSA 2009. [Consulted 2013 Apr 20]. Available from: http://www.insa.pt/ sites/INSA/Portugues/Publicacoes/Outros/Documents/Epidemiologia/ INS_05_06.pdf.

3. Carmo I, Santos O, Camolas J, Vieira J, Carreira M, Medina L, et al. Overweight and obesity in Portugal: national prevalence in 2003-2005. Obesity Rev. 2008;9:11-9.

4. Kreuter MW, Chheda SG, Bull FC. How does physician advice influence

patient behavior? Evidence for a priming effect. Arch Fam Med. 2000;9:426-33.

5. Oberg EB, Frank E. Physicians' health practices strongly influence patient health practices. J R Coll Physicians Edinb. 2009;39:290-1.

6. Bleich SN, Bennett WL, Gudzune KA, Cooper LA. Impact of physician BMI on obesity care and beliefs. Obesity. 2012;20:999-1005.

7. Chou CF, Johnson PJ. Health disparities among America's health care providers: evidence from the Integrated Health Interview Series, 1982 to 2004. J Occup Environ Med. 2008;50:696-704.

8. Caban AJ, Lee DJ, Fleming LE, Gomez-Marin O, LeBlanc W, Pitman T. Obesity in US workers: The National Health Interview Survey, 1986 to 2002. Am J Public Health. 2005;95:1614-22. 


\section{Body Mass Index Assessment of Health Care Professionals in a Primary Care Setting in Portugal: a Cross Sectional Study}

Acta Med Port 2014:27:609-614

Publicado pela Acta Médica Portuguesa, a Revista Científica da Ordem dos Médicos

Av. Almirante Gago Coutinho, 151

1749-084 Lisboa, Portugal.

Tel: +351218428215

E-mail: submissao@actamedicaportuguesa.com

www.actamedicaportuguesa.com

ISSN:0870-399X | e-ISSN: 1646-0758

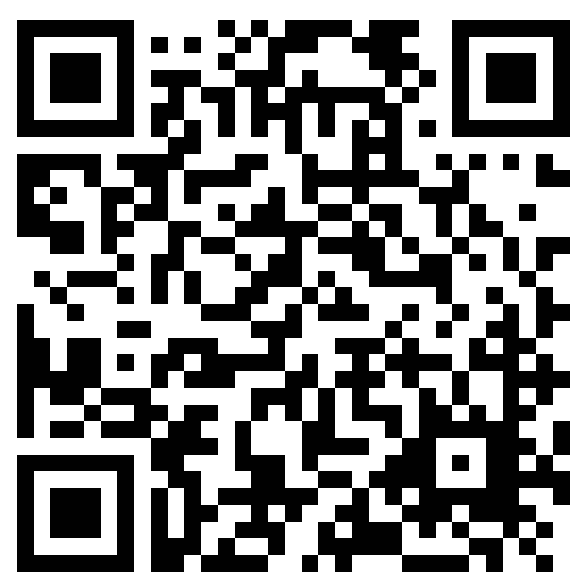

